\title{
Scalable Concentric Diversification Approach to Food Production for Sustainability in Rural Communities
}

\author{
Joe Essien \\ School of Computing and Technology, \\ University of West London, St Mary’s Road, Ealing \\ London, U.K
}

\begin{abstract}
Over the years, there have been many attempts by renowned bureaucrats, researchers and practitioners to define the term "agricultural diversification" and to enact farm policies that enforce that definition as tradition. These advocates claim that diversification, as it were, would provide greater income stability allowing specialized farms to benefit from economies of size. Foreign governments and international food aid organizations would not finance farming activities outside the scope of this definition. However, many critics contend that these definitions are misleading and do not necessarily lead to food security and agro-business sustainability. They argue that if it were so, poverty levels in the world would have reduced by now. Be that as it may, many foreign countries have a different understanding of the term "diversification". For instance, The British Department for Environment, Food and Rural Affairs (DEFRA) defines diversification as the entrepreneurial use of farm resources for a nonagricultural purpose for commercial gain. Many critics believe this to be a more appropriate and articulate definition of the concept as it reduces risk, accommodates responses to changing consumer demands, acknowledges changing government policies, malleable to external shocks and, more recently, as a consequence of climate change. It is as a result of this backdrop of what makes agricultural diversification a success or failure that the concept of scaleable concentric diversification approach to food production for sustainability is introduced. The research explores ways in which this intrinsic nuance can be implemented in rural communities for food production, security and sustainability.
\end{abstract}

Keywords: Food Security, Diversification, Sustainability, Food Policy, Communities, Farm, Food Production.

\section{INTRODUCTION}

In agriculture, diversification has been given so many meanings that it seems to be gradually losing its native quintessence and thwarting efforts of reducing food insecurity. It now tends to fit any activity that has extensions and variations whereas the idiomatic inference of diversification implies that one should not put all his eggs in one basket or "do not concentrate all your prospects or resources in one thing or place, or you could lose everything". Yet many rural farmers do exactly this and refer to the exercise as diversification. Diversification simply means not investing every resource you have in one venture. For example, if you put all your finances split in different amounts in one stock, or all your money in different stocks owned by one institution, or all your finances in buying real estates in one particular city, you have not truly diversified. The reason is that if the stock market crashes or estate business collapses in that city, all your investments in stocks or estates plunges down the drain. Yet most agriculturist, researchers and farmers believe very fervently that when they interweave the plantation of wheat, rice, cereals, pulses, cotton, sugarcane, jute, oilseeds fruits, vegetables in one or multiple acreages, they have diversified. Alternatively, that when they intermingle crop plantation with livestock or poultry in the same or multiple homesteads, they have diversified. To underpin this believe, some very cogent and widely accepted definitions of agricultural diversification are given;

"The term 'Agricultural diversification' as it applies to the area of agriculture can be defined as a system of farming that encourages production of a variety of plants and animals and their products as opposed to monoculture on a large-scale of specialization" [1].

"The Agricultural Diversification Project aims to diversify and intensify agricultural production so as to increase and stabilize farmers' incomes and rural employment in the poor provinces" [2]. 
International Journal of Advances in Scientific Research and Engineering (ijasre), Vol 5 (4), April-2019

"Agricultural Diversification is the practice of producing a variety of crops or animals, or both, on one farm, as distinguished from specializing in a single commodity" [1]

Agricultural Diversification is a system of farming that encourages production of a variety of plants and animals and their products, [3].

It is therefore not surprising that out of this tenacious misrepresentation of the concept by renowned authorities, researchers and critics have contrived other terms like "crop diversification", "diversified farming", "non-farm diversification", "farm diversification" and attributed their own definitions in order to remain within the conclaves of the complex system. While advocates of diversification as it were argue that this provides greater income stability allowing specialized farms to benefit from economies of size, some critics are convinced that it is not necessarily so and does not lead to food security and agro business sustainability. They argue that if it were so poverty levels in the world would have reduced and many farmers would not simply wane (ceteris paribus) even when there are favourable climate conditions as there is always demand for food. Wiki for instance does no accept the definition of agricultural diversification as commonly stated. Many authors define diversification as;

"In the agricultural context, diversification can be regarded as the re-allocation of some of a farm's productive resources, such as land, capital, farm equipment and pices to other farmers and, particularly in richer countries, non-farming activities such as restaurants and shops. Factors leading to decisions to diversify include but not restricted to reducing risk, responding to changing consumer demands, responding to changing government policy, responding to external shocks and, more recently, as a consequence of climate change. [4].

This, without a doubt is believed to be a more meaningful and articulate definition of the concept. In this paper, it is strongly opine that if these were the principles disseminated and encouraged universally, farming even in rural communities will be far more viable and sustainable. Even the British Department for Environment, Food and Rural Affairs (DEFRA) defines diversification as "the entrepreneurial use of farm resources for a non-agricultural purpose for commercial gain" [5]. It is as a result of this understanding of what makes agricultural diversification to succeed or fail that the concept of scaleable concentric diversification approach to food production for sustainability is introduced.

Concentric refers to a type of business strategy where the enterprise acquires or creates new products or services to reach more consumers. These new products and services typically are close derivatives to the company's existing products and services. This enables the enterprise to expand into new markets or industry which the business is not currently in, whilst creating a values for that new market. Applied in agriculture, it relates to the technique whereby the farmer extends the business of farming by creating new products or services closely related to existing agricultural produce being harvested. For instance, if a farmer plants and harvests cocoa, the farmer may diversify into an industry that produces butter, beverages and chocolates. Produce from palm tree which blossoms naturally in the rural tropical regions of Africa can be processed through diversification into cream, oil, dye, soap, wine, mulch and more. Likewise, if a farmer specialises on the growth of cassava and corn, he may diversify into the production of starch and flour. These refinements of the raw produce now become more economically veritable, exportable and yield far more revenue than just selling them in their innate state as done by the rural farmers. This is the true meaning of diversification as defined by DEFRA and some authors [5], [8], [12]. The major psychological dissoluteness plaguing the mindset of the native rural farmer is that the native rural farmer is contented selling cocoa beans, palm nuts, cassava and corn instead of textured improvements of their produce (butter, beverages, chocolates, cream, oil, dye, soap, wine, starch, flour, etc) which are far more economically viable. This is the proper diversification implied by DEFRA and practiced in developed economies. The rural farmers have been superfluously brainwashed to believe that planting maize, cassava, vegetables and other crops intermingled with birds and goats is agricultural diversification. This paradigm needs to be shifted if the world is exorable about eradicating poverty and ensuring food security in the nearest future.

Subsequently, the objective of this article is to propound strategies whereby rural farmers can revaluate their operations and determine the various dimensions through which they can collaborate and enhance their household income from sources other than conventional farming produce through proper diversification. Diversification in its fundamental sense is widely held to offer considerable scope for improving the economic viability of many farm businesses and in turn reduce their dependence on subsidised agricultural commodities. Such diversification in Agricultural practise would not only have immense impact on rural economies but also on rural development and environment conservation.

Having grounded the disparities in the concept of diversification as the underpinning subject of this discourse, the ensuing sections of this work are organised as follows. Section two addresses the dilemmas, challenges, pros and cons of agricultural diversification; section three delves into the relevance of diversification in rural communities; section four presents a model of the outcome of effective diversification while section five concludes this discourse with a recommendation for review of food policy regarding diversification. 
International Journal of Advances in Scientific Research and Engineering (ijasre), Vol 5 (4), April-2019

\section{THE DILEMMAS OF AGRICULTURAL DIVERSIFICATION POLICIES}

It as been suggested that the major advantages of agricultural diversification are to cope with variant consumer demands, adapt to changing demographics, utilize developing export potentials, add value, take advantage of emerging marketing opportunities and improve nutrition [6]. However, many critics believe that, given the way in which diversification is promulgated and in the context of sustainability, this may not necessarily lead to success as the threats are ferocious and far exceeds its benefits [2],[3], [4]. These risks include urbanization, market risk, risk from bad weather, external threats for farmers who depend on exports, risk from change in consumer demand, risk from policy variations, risk from endemic pestilence, risk from desiccation, domestic policy threats and climate change. Consequently, it is not surprising that the level of poverty in the world and the wellbeing of rural farmers have not significantly changed over decades of commitment, though almost all farmers are engaged in diversified agriculture.

For the propose of funding and agricultural aid many institutions including World Bank accept Agricultural diversification only as projects aimed to diversify and intensify agricultural production in the poor provinces [7]. This definition strictly implies extreme dependency of farmers in poor developing countries on agriculture as a source of livelihood and works on the supposition that diversification basically involves the subsistence of one crop with other crops or livestock or increase on the size of farming activities. The indication of the meaning of this statement is that World Bank would not promote diversification as the entrepreneurial use of farm resources for a non-agricultural purpose for commercial gain and would not provide financial aid for such activities. Also, in the United Kingdom, the England Rural Development Programme (ERDP) would not accept any other activities outside this realm as agricultural endeavour [8].

However, many other developed countries and institutions, again including the British Department for Environment, Food and Rural Affairs (DEFRA) define diversification differently for their own enthusiasts. Agricultural diversification is accepted as the entrepreneurial use of farm resources for a non-agricultural purpose for commercial gain [9]. These developed countries would provide funding within their jurisdiction for these types of activities for their aboriginal farmers. Obviously, the developed countries have realised that these are the activities that would bring more development to the community, generate more returns that can be ploughed back into the agricultural practice as well as boost their economy. To affirm this notion, a research carried out by DEFRA found that $56 \%$ of UK farms had diversified in 2003 . The great majority of diversification activities simply involved the renting out of farm buildings for non-farming use. It also discovered that $9 \%$ of farms had become involved with processing or retailing, 3\% with provision of tourist accommodation or catering and $7 \%$ with sport or recreational activities [5],[9]. This demonstrates that relaxing the restrictions on policies governing rural farmers to encompass broader activities would ultimately boost other kinds of entrepreneurial activity including food production, food security and development of new marketing opportunities. The food policies should include obvious activities such as tourism, sport, recreation, food processing and production of organic crops which remain agricultural activities. Without introducing flexibilities into food policies especially as it relates to diversification, extant policies simply stifles development amongst rural farmers and inhibits economic emancipation and food security. For this reason also, agricultural diversification projects which should aim to expand and intensify wealth creation and sustainability so as to increase and alleviate farmers' incomes and rural advancement are acutely constrained. This is the reason the farmers who produce sugarcane and sugar beet for instance remain miserly poor when compared with the multinational establishments who buy the produce, process it and sell as sweetener to food processing industries. Sugar cane accounts for about $80 \%$ of the world's sugar production, while sugar beet accounts for the remaining $20 \%$, but the farmers who plant them remain amongst the poorest in the world. This is one of the reasons why native rural farmers who produce cocoa, wheat and maize, the most planted staples throughout the world are poverty-stricken while the moguls of food beverage, chocolate and flour industries that buy the raw produce and diversify in the proper sense of the concept prosper immensely. This is the very same reason developing countries that produce crude oil for instance remain poor when compared to multinationals and countries that buy the product, refine it and sell it back at excessively disproportionate price to the producers. True concentric diversification is stifled by means of repressive policies just like many other commodities produced worldwide by poor provinces.

\section{WHY AGRICULTURAL DIVERSIFICATION IS VITAL FOR RURAL TRANSFORMATION}

Many researchers have delved into the benefits and symbiosis of the coexistence of the farm sector and non-farm sector in rural communities [10], [11], [12]. Findings from these authors indicate that for sustainable food security and economic growth to thrive in rural economy, these two sectors must complement each other efficiently and effectively. Farm activities include agriculture (crop production), plantation, animal husbandry (milk, meat, egg etc), forestry \& logging and fishing, whereas the nonfarm sector includes all other activities like agro-processing industries, wholesale and retail trading, storage and communication, transport and education, health industries and other service related activities. It is completely impossible for the farm sector to flourish on its own without a means to store the produce, preserve the produce, transport the produce to markets, service machinery, and so on. A farmer that depends solely on external corporations to provide these services will definitely fail 
especially in rural communities. These non-farm sectors are also viable businesses for those who engage in it. So the question is, should the farmer diversify into these sectors which guarantee the continuity of his business or should the farmer grow more varieties of crops? By adopting scalable concentric diversification over time, the economy grows and tends to be transformed generally. Transformation means movement of the economy from one stage to another stage of development. The well-known pattern of transformation that has been experienced by the countries at different stages of development is the movement from agriculture (farm) to manufacturing and then to services. As the overall economy goes through the process of transformation, the rural farmer and the economy will also follow the similar process of transformation. Adoption of scalable concentric diversification increases agricultural output manifold. Undoubtedly, as productivity increases, the average farm income would increase. As a result of increase in production, there is also a corresponding increase in the marketable surplus. The subsistence farm economy which starts producing for the market becomes market oriented. Farmers in rural areas will no longer be dependent on the local markets for the maintenance of machinery as well as for selling the farm output. As the market expands, so would the farmer's supply decisions driven by the market indicators. Progress in concentric diversification would lead to efficient commercialization and capitalization of the farm economy and hence of the rural community. As production increases, agricultural demand for trading services, storage and communication would increase concurrently. Need for improved transport and storage which supports the farm business in handling distribution and marketing would intensify. Jobs will be created. Bigger farms can commercialize theirs facilities to smaller farms. The economy would grow.

Technological development and adoption of new technologies as a phase of concentric diversification by the farmers can facilitate online marketing and advertisements. Repair shops for agricultural mechanisms and arming tool would ensure that tilling, planting and harvesting are not hampered and can serve as extension services. So the non-farm economy in the rural areas gets enhanced via the production associations. Apart from this, as average farm income increases, consumption of non-farm goods (consumer durables either produced locally and outside the rural areas) increases (consumption linkage). Increased demand for consumer goods and services culminates in expansion of the rural manufacturing subdivision and service sectors providing education and medical amenities, insurance and banking services. Concentric diversification of the rural farm activities can play important roles in reducing the widespread rural poverty through generation of employment and income and creation of effective demand for goods and services. The role becomes significant as it can offer diverse employment opportunities to the rural dwellers and in the process transform the rural economy. Concentric diversification may proceed in two directions: increasing diversity of activities and increasing the scale of the existing activities. The former refers to employment and institutional diversification, defined as the increase in the number of opportunities of labour and hence of more income for a farm household, the latter increases the employment capacity implicitly and explicitly. Concentric Diversification is the process by which a rural household constructs a varied portfolio of non-farm activities for survival. It also improves his paradigm of existence and business continuity. Adopting this approach and diversifying away from core planting and breeding activities of farming helps the transformation of the rural economy in the following ways; (i) increases income of the rural people considerably as non farm wage is usually higher than agricultural wage, (ii) provides security and reduces the risk and uncertainty associated with farm income, (iii) reduces the pressure of labour on land and (iv) reduces the tendency of the rural people to migrate to urban areas. The extent to which the rural farm and non-farm activities have undergone any structural change is a matter of policy stipulations in support for its implementation and funding.

\section{TYPES AND STRUCTURE OF CONCENTRIC DIVERSIFICATION}

Moving from food crisis to food Sovereignty demands that everyone has the right to enough resources to feed. Many developed countries have been practicing the true Concentric Diversification for years, with solid results in the fight against hunger and poverty. Concentric Diversification deploys a schema developed as organisational principles and guidelines. Procedures are well stipulated for both internal and external clients as a standard business concern. Large scale farmers use their facilities to support small scale farmers within the same vicinity, directly addressing the root causes of hunger, poverty and inequality.

Together they not only restructure control over the efficiency of food production, but also restructure market power. It also contributes towards defining national food and agriculture policies as well as increasing biodiversity. Concentric diversification has the potential to radically change food production systems in favour of the poor especially in the rural areas. We will examine both the structure and opportunities that can be harnessed from concentric diversification. 


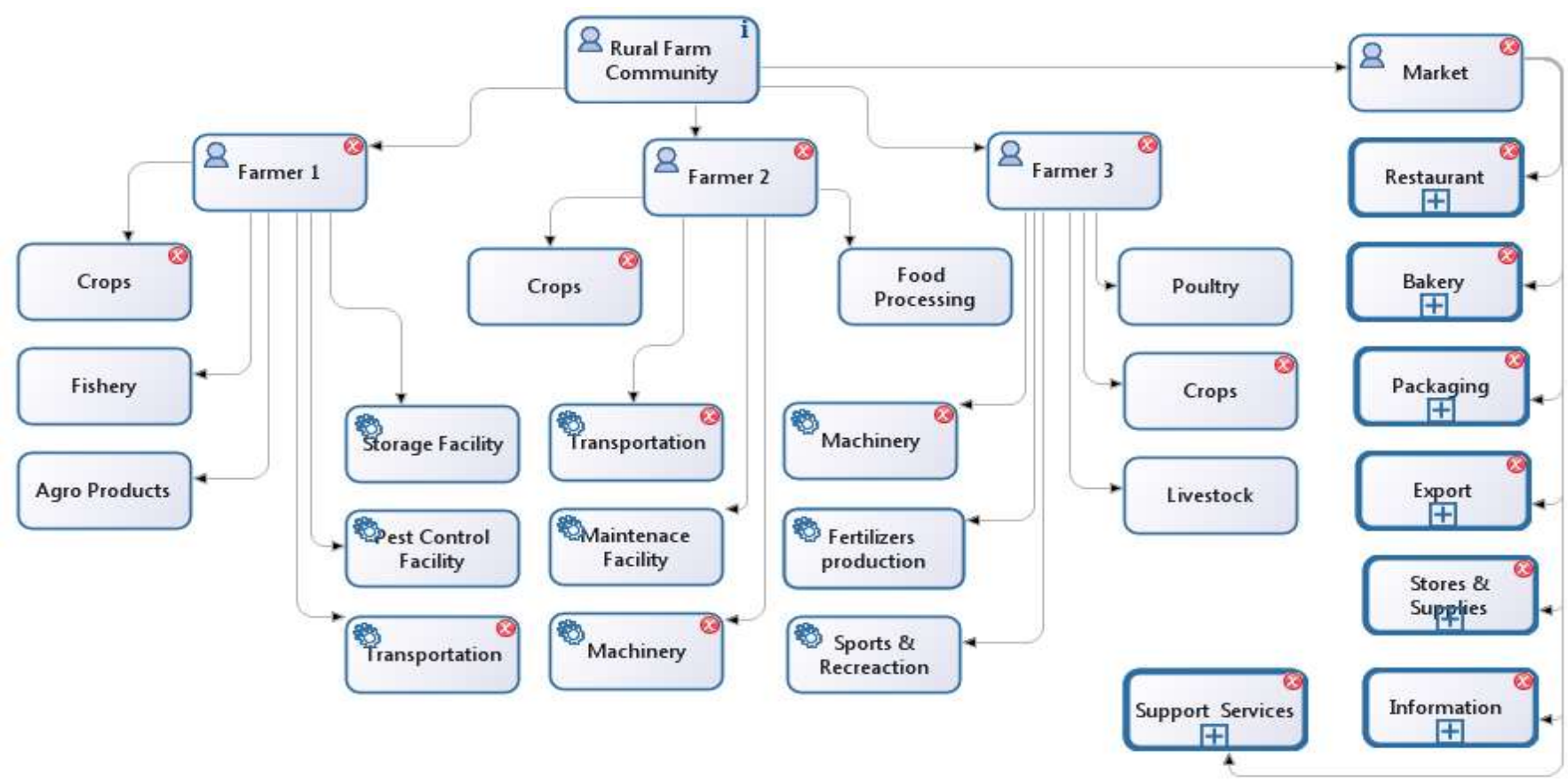

Figure 1: Interrelationship of the Concentric Diversification Approach

Figure 1 depicts a model within rural economy where concentric diversification is practiced. The entities with the setting icon represent the concentric aspects of the diversification. Because these diversifications exist within the same community, they provide support for each other thus ensuring their sustainability as well as enhancing the core business of food production. Also within the markets, additional diversification can occur all sourcing from the produce from the farms. Without the concentric diversification, this transformation within the rural community can not exist. If diversification implied growth of varieties of crops, it would make little or no difference to the transformation of the rural community. A diversified portfolio of crops alone does not ensure that farmers do not suffer devastating ruins from endemic pestilence and desiccation. Even the poultry can be affected by climate change and pestilence. To end hunger, there need to be fundamental shift in policy making, the balance of technological innovations with food production systems so that the interests of the farmers as well as consumers are served. Broadening the scope of diversification and services would shift understanding of food systems from normative constructed practices to corporate logic of inclusiveness, collaboration, and high-level integration. The question is not therefore how food sovereignty can be solved but how the various added values of concentric diversifications can be integrated to boost production and alleviate poverty in the rural farming communities of developing economies.

Concentric diversification is an important mechanism for economic growth. It depends however on identification of opportunities for diversification and on farmers' responsiveness to those opportunities. Concentric diversification can be facilitated by technological breaks through, by changes in consumer demand or in government policy or in trade arrangements, and by development of access roads, and other infrastructures. Conversely, it can be impeded by risks in markets and prices and in management practices, by degradation of natural resources, by conflicting socio-economic requirements including employment generation, funding policies, self-sufficiency, foreign exchange availability and capacity building.

\subsection{Horizontal Integration}

Horizontal integration is the act of integrating other infrastructures, assets and companies of the same industry or in the same level of production. The acquisition of these assets typically results in an expansion of existing operations rather than the establishment of new operations. An example of horizontal integration would be one restaurant chain buying another or one food manufacturing company purchasing another food manufacturing company.

\subsection{Horizontal Integration Benefits}

The principal advantage of engaging in horizontal integration is that it abdicates competition from other organizations. This is because the assets that it integrates are intrinsic, used by competitors to go after the same market sector. It also serves comparatively as a cheap means of breaking into new markets because, rather than engaging in many researches, analysis and litigation issues involved with opening a new enterprise, it allows a business to take control of an outlet that already exists. However, governments tend to frown on horizontal integration for some reasons. This is because, if a single entity takes control of 
an entire market in this way, it becomes a monopoly, which means that it can charge exorbitant prices with little fear of losing business.

\subsection{Vertical Integration}

Vertical integration is the act of expanding into new operations for the purpose of decreasing a firm's reliability on other firms in the process of production and distribution. Such integration requires firms to undertake new aspects of business operations. An example would be a supermarket firm that, instead of contracting with freight companies, purchases its own trucks and distribution facilities that it uses to get food items and household products out to its various locations.

\subsection{Vertical Integration Benefits}

The major advantage of vertical integration is that it allows firms to reduce total costs by internalizing the value that other companies would otherwise take as profits. For instance, a farm may pay a trucking firm $£ 6,000$ to do something that only costs the trucking firm $£ 2,500$. By buying its own truck and hiring an employee driver, the farm only has to pay $£ 2,500$ for the same service. The main challenge that discourages firms from engaging in vertical integration are the uncertainties associated with engaging in an unknown type of operations and the up-front capital that such integration efforts may require.

\subsection{Concentric diversification based on technological capabilities}

This research responds to the needs for concentric diversification by focusing on how organizations can find new business opportunities based on their production capabilities. A scalable approach is proposed to identifying potential areas for concentric diversification at a product level through link analysis of products and technologies. For this; firstly, data mining is carried out to determine the extent of concentric diversification and collaboration required. Secondly, collaborative policy review is carried out to determine systems complexities using focussed technological relationships between products and services. Thirdly, an associative predictive analysis is conducted to identify potential areas for extending the at a produce level. Finally, quantitative indicators are deployed to assess the characteristics of the areas identified. It is envisioned that the proposed approach would be useful as a complementary tool for decision making for small and medium sized farms that are considering entering new business areas but have minimal domain knowledge.

\section{CONCLUSIONS}

Concentric Diversification should be considered as part of the long-term time dimension in the assessment of food security. From such a perspective the conception of sustainable food can constitute a primary role as a deliverable and a means of maintaining dietary health and well-being, while ensuring the sustainability for future food security. Without integrating concentric diversification as an explicit dimension of food security in today's policies and programmes, achieving food sustainability can emerge as the very albatross of decreased food security in the future. The two concepts of food security and sustainability share several attributes with concentric diversification. The term "agricultural diversification" is a broad and complex concept used by various institutions non-governmental organizations and governments, which each often coining their own definitions. They term has been designed to signify and represent common objectives for the developed countries but different meaning and connotation for developing countries. With sustainability within food systems becoming progressively more significant issue, numerous approaches have been asserted to assess the sustainability of farms, farming systems, and supply chains. Scrutinizing more intimately these sustainability impact assessment approaches, substantial differences are noticed between them in terms of capacity, the measure of evaluation, and the exactitude of indicators used for impact assessment. Therefore, the objective of this article was to propound strategies whereby rural farmers can revaluate their operations and determine the various dimensions through which they can collaborate and enhance their household income from sources other than conventional farming produce through concentric diversification. It is recommended that food policies should look again into the precise definition of "agricultural diversification" harmonize its meaning, activities, involvements globally in order to enable donor institutions to provide funds that would facilitate development in rural agricultural communities. Sustainability Assessment in Food and Agriculture Systems (SAFA) Guidelines would be of tremendous help in clarifying this ubiquity in order to make the concept more analogous.

\section{REFERENCES}

1. Van Huylenbroeck, Guido, et al. "Multifunctionality of agriculture: a review of definitions, evidence and instruments." Living reviews in landscape research 1.3 (2007): 1-43.

2. Azam-Ali, Sayed. "Agricultural Diversification: The Potential for Underutilised." Rivista di Biologia/Biology Forum. Vol. 100. 2007. 
3. Lin, Brenda B. "Resilience in agriculture through crop diversification: adaptive management for environmental change." BioScience 61.3 (2011): 183-193.

4. Bowman, Maria, and David Zilberman. "Economic factors affecting diversified farming systems." Ecology and Society 18.1 (2013).

5. DEFRA, Diversification in Agriculture Archived June 9, 2007, at the Wayback Machine.

6. Birthal, Pratap Singh, et al. Diversification in Indian agriculture towards high-value crops. Vol. 727. Intl Food Policy Res Inst, 2007.

7. Havnevik, Kjell, et al. African agriculture and the World Bank: development or impoverishment?. Nordiska Afrikainstitutet, 2007.

8. Ward, Neil, and Philip Lowe. "Europeanizing rural development? Implementing the CAP's second pillar in England." International Planning Studies 9.2-3 (2004): 121-137.

9. Foster, Chris, Ken Green, and Mercedes Bleda. "Environmental impacts of food production and consumption: final report to the Department for Environment Food and Rural Affairs." (2007).

10. Bhattacharya, Amar, Jeremy Oppenheim, and Nicholas Stern. "Driving sustainable development through better infrastructure: Key elements of a transformation program." Brookings Global Working Paper Series (2015).

11. Escobar, Arturo. Encountering development: The making and unmaking of the Third World. Princeton University Press, 2011.

12. Scoones, Ian. "Livelihoods perspectives and rural development." The journal of peasant studies 36.1 (2009): 171-196. 